\title{
Tecnologias móveis e relações interpessoais: refle- xões sobre comportamento e aprendizagem
}

\section{Resumo}

Magnus Guerreiro Thomazini

Elias Estevão Goulart

Universidade Municipal de São Caetano do Sul

As emoções fazem parte inerente da natureza e das relações humanas e sociais. Os processos educativos são influenciados pelas emoções dos estudantes que determinam seus comportamentos e possibilidades de aprendizagem. As tecnologias digitais móveis estão presentes no cotidiano dos estudantes e exercem influência na sua atenção, comportamento e relacionamentos, inclusive com conotações negativas pela priorização das interações virtuais em detrimento das presenciais. $\bigcirc$ estudo de natureza exploratória, com abordagem quali-quantitativa, visa identificar os fatores prevalentes na importância das tecnologias para estudantes, e compreender seu significado e presença na vida dos alunos. Foram entrevistados 150 alunos da série final do ensino fundamental, de duas escolas municipais do município de São Caetano do Sul. A pesquisa analisou relacionamentos interpessoais desses alunos, a relação com a aprendizagem no contexto escolar e a importante presença das mídias digitais na rotina deles. Como resultado, foi elaborada uma Matriz de Referência de Orientação Emocional.

Palavras-chave: Educação. Tecnologias digitais móveis. Emoções. Aprendizagem.

\section{Mobile technologies and interpersonal relationships: reflec- tions on behavior and learning}

\section{Abstract}

Emotions are an inherent part of the nature and the human and social relationships. Educational processes are influenced by the emotions of students that determine their behaviors and learning possibilities. Mobile digital technologies are present in students' everyday life and exert an influence on their attention, behavior and relationships, including negative connotations, by prioritizing virtual interactions over face-to-face interactions. The exploratory nature study, with a qualitative-quantitative approach, aims to identify the prevalent factors in the importance of technologies for students and to understand their meaning and presence in students' lives. We interviewed 150 students from the final grade of Middle School from two municipal schools in the municipality of São Caetano do Sul. The research analyzed the interpersonal relationships of these students, the relationship with learning in the school context and the important presence of digital media in the routine of these students. As a result, we elaborate a Reference Matrix of Emotional Guidance.

Keywords: Education. Mobile digital technologies. Emotions. Learning. 


\section{Tecnologías móviles y relaciones interpersonales: reflexiones sobre el comportamiento y el aprendizaje}

\section{Resumen}

Las emociones forman parte inherente de la naturaleza y de las relaciones humanas y sociales. Los procesos educativos son influenciados por las emociones de los estudiantes que determinan sus comportamientos y posibilidades de aprendizaje. Las tecnologías digitales móviles están presentes en el cotidiano de los estudiantes y ejercen influencia en su atención, comportamiento y relaciones, incluso con connotaciones negativas por la priorización de las interacciones virtuales en detrimento de las presenciales. El estudio de naturaleza exploratoria, con abordaje cualitativo/cuantitativo, busca identificar los factores prevalentes en la importancia de las tecnologías para estudiantes, y comprender su significado y presencia en la vida de los alumnos. Se entrevistaron a 150 alumnos de la serie final de la enseñanza fundamental, de dos escuelas municipales del municipio de São Caetano do Sul. La investigación analizó relaciones interpersonales de estos alumnos, la relación con el aprendizaje en el contexto escolar y la importante presencia de los medios digitales en la su rutina. Como resultado, se creó una Matriz de Referencia de Orientación Emocional.

Palabras clave: Educación. Tecnologías digitales móviles. Las emociones. El aprendizaje.

Educating the mind without educating the heart

is no education at all.

- Aristotle, 344ac.

\section{Introdução}

Historicamente, no contexto escolar, sabe-se que a afetividade não era foco considerado na relação ensino-aprendizagem. À escola, reservava-se o papel da transmissão dos conteúdos de relevância acadêmica e, nessa perspectiva, cabia ao professor 'ensinar' a matéria e, ao aluno, 'aprendê-la'. No início do século XX, o educador francês Henry Wallon (1971) contrapõe-se a essa ideia e ressalta, através de sua teoria de aprendizagem centrada no sócioconstrutivismo, o conceito da afetividade como um dos aspectos centrais do desenvolvimento. Ao estudar a criança, o pesquisador citado defende que o desenvolvimento dos aspectos motor, afetivo e cognitivo está interligado, coexistindo e atuando integralmente, afetando um ao outro indissociavelmente. Segundo esse teórico, os elementos externos (como os olhares, palavras, 
objetos, informações e estímulos) e as sensações internas (como o medo, alegria, raiva, tristeza e fome) agem sobre o indivíduo e este responde a eles. A essa condição humana define-se a afetividade, ou seja, aquilo que afeta, significativamente, a formação do ser.

Segundo Wallon (1971), a afetividade corresponde à primeira forma de interação do indivíduo com o meio ambiente. $\bigcirc$ afeto, segundo o pesquisador, é o elemento mediador das relações sociais enquanto as emoções constituem a base do desenvolvimento da inteligência. Tratando-se de 'sentimento' em sala de aula, parte-se do princípio de que essa disposição não pode ser recalcada, reprimida ou desconsiderada.

Para que a aprendizagem efetiva aconteça, a relação entre professores e educandos precisa estar pautada na compreensão das emoções, tirando-os da defensiva e eliminando distanciamentos hierárquicos e o ranço acadêmico, que, muitas vezes, são confundidos com respeito, facilitando a troca entre esses dois personagens (FERREIRA; MARTURANO, 2002).

Analisando as pesquisas de Chabot e Chabot (2005) para fundamentar teoricamente a importância das emoções no processo escolar, o tema em 170 questão é abordado na perspectiva de que a aprendizagem não se dá apenas no âmbito cognitivo. Sem desmerecer sua relevância, parte-se do princípio de que o aspecto cognitivo é insuficiente e incapaz de responder a todas as questões relativas ao aprendizado e às suas dificuldades.

Neste sentido, torna-se importante analisar e aprofundar este estudo embasando-se nas teorias de Goleman (2005) - Inteligência Emocional, e Gardner (1998) - Inteligências Interpessoal e Intrapessoal, as quais revelam os motivos de considerar as emoções no ambiente escolar, enfatizando a necessidade de desenvolver a qualidade das relações entre os agentes.

Para compreender o perfil dos estudantes, discute-se, à luz de Greenfield (2011), Eisenstein e Estefenon (2011), entre outros, o papel das tecnologias digitais no contexto dos novos comportamentos de crianças e jovens, especialmente das tecnologias móveis, como smartphones e tablets, e sua influência nas relações interpessoais, com especial atenção no ambiente educacional.

Em seguida, apresentam-se a descrição e o enfoque da pesquisa, as questões relativas ao corpus do estudo, a abordagem quanto ao método e procedimentos escolhidos, evidenciando o papel que as emoções ocupam nas 
relações interpessoais e suas relações no cotidiano escolar, nesse amálgama que é o processo ensino-aprendizagem.

\section{As relações interpessoais e intrapessoais no ambiente escolar}

As relações interpessoais e intrapessoais no âmbito escolar têm chamado cada vez mais a atenção de estudiosos, como Goleman (2005), Gardner (1998), Chabot e Chabot (2005), que buscam compreender e analisar os comportamentos que permeiam o contexto da sala de aula. Intolerância, desrespeito, injustiça, agressividade, na relação professor-aluno e entre os pares são queixas frequentes de muitos docentes. Analisar esses comportamentos que interferem, significativamente, no bom andamento escolar tem sido alvo de algumas pesquisas dos autores citados.

Segundo Gardner (1998), as relações interpessoais constituem uma inteligência específica que envolve a capacidade da percepção e distinção de sentimentos em outros indivíduos, além de intenções, motivações, humor, sensações e intenções que as pessoas mostram. Para o autor, a inteligência interpessoal tem, como base, a real percepção de contrastes em diferentes estados de ânimo, temperamentos, emoções e intenções, levando a pessoa com tal habilidade e inteligência a perceber as intenções e desejos de outras pessoas, ainda que estes não estejam evidentes ou aparentes. Afirma o referido autor que a inteligência interpessoal é bastante valorizada nas relações sociais, uma vez que seu domínio garante a interação saudável, cooperativa e desperta a liderança na organização e atividades em grupo.

Gardner (1998) conceitua outro tipo de inteligência, também considerado de alta relevância no contexto escolar, a intrapessoal. Trata-se, segundo o autor, do autoconhecimento das suas emoções, habilidades, limitações, desejos e sensações e a capacidade de se adaptar com base nesse conhecimento. Tal inteligência, para o autor, determina também a capacidade de autodisciplina, autoentendimento e autoestima. Com capacidade para identificar suas próprias emoções, o indivíduo, com inteligência intrapessoal bem desenvolvida eventualmente poderá utilizá-las como maneira de entender e orientar o próprio comportamento, manifestando o desejo de conhecer a si próprio, de refletir sobre seus erros e de aprender com eles, adequando seu comportamento ao melhor convívio social. 
Tecnologias móveis e relações interpessoais: reflexões sobre comportamento e aprendizagem

Seguindo o mesmo contexto das necessidades e fatores determinantes para o bom relacionamento interpessoal, a inteligência emocional está apontada como fator fundamental, uma vez que:

As pessoas com prática emocional bem desenvolvida têm mais probabilidade de sentirem-se satisfeitas e serem eficientes em suas vidas, dominando os hábitos mentais que fomentam sua produtividade; as que não conseguem exercer algum controle sobre a vida emocional travam batalhas internas que sabotam sua capacidade de se concentrar no trabalho e pensar com clareza (GOLEMAN, 2005, p. 26).

Considerando as definições de Gardner (1998) já citadas sobre as inteligências interpessoais e intrapessoais e, atendendo às proposições de Goleman (2005), acerca da importância do desenvolvimento da inteligência emocional para estabelecer um relacionamento interpessoal salutar, considera-se, de especial relevância, a abordagem desse conteúdo com toda sua complexidade no contexto escolar, o qual é permeado, em sua totalidade, por relações entre os agentes que lá se encontram: professores, alunos, equipe técnica, profissionais de apoio, familiares. Assumir a necessidade de avançar no desenvolvimento emocional de todos esses agentes e promover ações que permitam tal avanço constituirão o grande desafio que poderá viabilizar a solução dos problemas de socialização apontados no início deste capítulo.

Para identificar os disparadores e comportamentos dos alunos no contexto escolar, o quadro 1 abaixo, apresentado por Chabot e Chabot (2005), mostra alguns exemplos de emoções, pertinentes ao aprendizado escolar.

Ao longo de todo o processo de aprendizagem, essas emoções estão onipresentes, interferindo significativamente, promovendo alterações nesse processo no contexto escolar. "Tudo se passa como se as emoções pudessem assumir o controle do conjunto de nossas funções cognitivas e perceptivas." (CHABOT, 2005, p. 85). As emoções negativas, de acordo com o autor, possuem um impacto ainda maior sobre as funções cognitivas e intelectuais, como a atenção, a percepção e a memorização, fundamentais para o sucesso escolar. Para o referido autor, as emoções negativas são responsáveis por um número considerável de dificuldades de aprendizagem, comprometendo efetivamente o desempenho do educando. Distinguir seus disparadores e compreendê-los é fundamental para desenvolver a inteligência emocional, a fim de 
otimizar emoções que geram comportamentos de aproximação e motivação, obtendo benefícios em sala de aula.

\section{Quadro 1}

\section{As emoções em relação à escola}

\begin{tabular}{|l|c|l|}
\hline \multicolumn{1}{|c|}{ Disparadores } & Emoções & \multicolumn{1}{c|}{ Comportamentos } \\
\hline $\begin{array}{l}\text { Desconforto no sistema } \\
\text { escolar }\end{array}$ & Insegurança (medo) & Evasão escolar (fuga) \\
\hline $\begin{array}{l}\text { Dificuldades em algumas } \\
\text { disciplinas (obstáculo) }\end{array}$ & Frustração (raiva) & $\begin{array}{l}\text { Crítica do sistema escolar } \\
\text { (ataque) }\end{array}$ \\
\hline Fracassos (perda) & Decepção (tristeza) & Desmotivação (retraimento) \\
\hline $\begin{array}{l}\text { Reprimendas e desprezo } \\
\text { (situação aversiva) }\end{array}$ & Humilhação (aversão) & Descompromisso (rejeição) \\
\hline $\begin{array}{l}\text { Feedback negativo } \\
\text { da parte do professor } \\
\text { (repulsa) }\end{array}$ & Menosprezo & $\begin{array}{l}\text { Réplica desrespei- } \\
\text { tosa ao professor } \\
\text { (condescendência) }\end{array}$ \\
\hline $\begin{array}{l}\text { Resultados inesperados } \\
\text { (situação inesperada) }\end{array}$ & Estupefação (surpresa) & Nervosismo (orientação) \\
\hline $\begin{array}{l}\text { Sucessos e encorajamen- } \\
\text { tos (situação desejada) }\end{array}$ & Entusiasmo (alegria) & $\begin{array}{l}\text { Motivação, interesse } \\
\text { (aproximação) }\end{array}$ \\
\hline
\end{tabular}

Fonte: Chabot e Chabot (2005).

Nesse sentido, Chabot e Chabot (2005) defendem que, para detectar emoções do aluno, faz-se necessário, inicialmente, partir da base da comunicação: praticar a escuta do que ele quer dizer. "O papel do educador será, em um primeiro momento, permitir que o aluno identifique, expresse e compreenda suas emoções e reconheça de onde elas proveem" (CHABOT, 2005, p. 152). Acompanhar o aluno, nesse processo de identificação, expressão e compreensão de suas próprias emoções, permitirá ao professor, segundo o referido autor, ajudar o educando a administrá-las, abrindo, assim, caminhos para melhorar o desempenho escolar.

À medida que o aluno progride na identificação e expressão de suas emoções, compreende, gradativamente, aquilo que vive. Para Chabot e Chabot (2005), o processo de compreensão seguirá a mesma ordem apresentada no ato de se expressar, ou seja, primeiro o sujeito compreende a situação 
vivida para, posteriormente, entender o comportamento manifestado na situação. Na última etapa desse processo, ocorrerá a compreensão das emoções sentidas.

A importância de decifrar o processo de expressão e compreensão justifica-se por toda a complexidade que permeia as relações interpessoais no ambiente escolar. As desordens e dificuldades, encontradas nessas relações e a não resolução de conflitos, levam à necessidade de melhor compreender como se dá o processo de elaboração das emoções, permitindo, assim, a condução das relações de maneira mais acertada e adequada (BOLSONI-SILVA; MARTURANO, 2002).

Entendendo o exposto e, partindo do princípio de que a busca pela qualidade das relações interpessoais na escola promoverá condições para efetiva aprendizagem do aluno, Chabot e Chabot (2005) reafirma que os avanços, na identificação e expressão daquilo que se sente em profundidade, dependerão da escuta ativa e real, ação que conduzirá à gestão das emoções nas relações interpessoais e intrapessoais. Saber ouvir o outro, com a finalidade de estimulá-lo a expressar suas emoções, e não apenas relatar uma série de acontecimentos, experiências e comportamentos, não acontece com

174 frequência, segundo o autor, pela dificuldade que as pessoas mostram para praticar a escuta verdadeira, ou seja, deixar o outro expressar tudo o que sente sem interrupções interpretativas ou julgadoras que desencorajam a narrativa.

A escuta ativa, a que se refere o autor, promoverá maior proximidade entre professor e aluno, desenvolvendo a qualidade desejada nas relações interpessoais para alcançar a aprendizagem efetiva no campo cognitivo, sendo, portanto, necessária nas habilidades docentes.

\section{O papel das tecnologias digitais e os novos comportamentos juvenis}

Tendo sido anteriormente abordada e fundamentada a importância de considerar o comportamento socioemocional dos alunos e a qualidade das relações interpessoais que transcorrem o processo de ensino e aprendizagem, acredita-se, no presente estudo, que se faz necessário também entender o papel das tecnologias digitais no contexto dos comportamentos de crianças e jovens do século XXI, uma vez que as mídias digitais estão presentes desde 
o nascimento deles. Desta forma, esses jovens, considerados nativos digitais, têm ao seu alcance vários recursos de comunicação em rede e acesso rápido à informação, tornando a Internet, o telefone celular e muitos outros equipamentos de tecnologia da informação comumente utilizados no cotidiano dos alunos nos diferentes contextos: familiar, social e escolar, perpassando, consequentemente, as relações interpessoais e o comportamento das crianças e jovens.

Validando a afirmação apresentada, Einsestein e Estefenon (2011) destacam que a era digital está mudando comportamentos, relacionamentos e estilos de vida, tendo a Internet atravessado fronteiras, rompendo barreiras físicas e culturais e crescendo de forma célere, chamando a atenção dos pais e dos profissionais da saúde, educação, segurança e comunicação. Segundo as referidas autoras:

Atualmente as crianças e adolescentes vivem em dois mundos: aquele que todos conhecemos, o mundo real, e o mundo digital ou virtual, que parece muito mais interessante e surpreendente, oferecendo aventuras, oportunidades, a busca pela autonomia, mas também, perigos e riscos à saúde. O espaço cibernético, o mundo da Internet e a velocidade da comunicação se tornaram o 'lugar vivo de verdade', onde todos se encontram, aprendem, jogam, brincam, brigam, trocam fotos, ganham dinheiro, começam e terminam amizades e namoros (EISENSTEIN; ESTEFENON, 2011 , p. 43).

A citação acima reforça a ideia apresentada no início deste capítulo quanto à importância de melhor compreender o universo dessa geração digital para explorar o uso da Internet como ferramenta de comunicação e acesso às informações de forma saudável, segura, educativa, ética, tornando as mídias digitais uma ponte de diálogo entre gerações, perfazendo a rotina de todos os profissionais que atendem a esse público e que estão preocupados com a qualidade das relações interpessoais e o desenvolvimento socioemocional dos mesmos.

Em seu artigo sobre a geração digital, Eisenstein e Estefenon (201 1) apresentam seus estudos quanto às mudanças de comportamento de crianças e adolescentes que convivem num mundo cada vez mais veloz e constante de transformação. $\bigcirc$ quadro abaixo, exposto no citado artigo, mostra o paralelo das características dessa geração que domina a tecnologia e do universo digital: 
Tecnologias móveis e relações interpessoais: reflexões sobre comportamento e aprendizagem

\section{Quadro 2}

Geração Digital: riscos para crianças e adolescentes

\begin{tabular}{|l|l|}
\hline \multicolumn{1}{|c|}{ Crianças e Adolescentes } & \multicolumn{1}{c|}{ Universo Digital } \\
\hline $\begin{array}{l}\text { Desafiam limites e transgridem regras } \\
\text { e horários }\end{array}$ & $\begin{array}{l}\text { Tudo é sem fronteiras, sem limites e sem } \\
\text { demora e simultâneo }\end{array}$ \\
\hline Fantasias e imaginação & $\begin{array}{l}\text { O anonimato garante a possibilidade de } \\
\text { mentir sobre qualquer coisa }\end{array}$ \\
\hline $\begin{array}{l}\text { Todos querem ter amigos e pertencer a } \\
\text { um grupo de iguais e sofrem a pressão } \\
\text { dos amigos }\end{array}$ & $\begin{array}{l}\text { Mundos real e virtual se confundem e são } \\
\text { criados novos códigos de relacionamen- } \\
\text { to, aumentam os contatos entre o grupo } \\
\text { de iguais, mas serão todos amigos? }\end{array}$ \\
\hline $\begin{array}{l}\text { Tornam alvos preferidos do consumis- } \\
\text { mo e da globalização digital }\end{array}$ & $\begin{array}{l}\text { Alvos de vendas on-line e da pirataria } \\
\text { digital }\end{array}$ \\
\hline $\begin{array}{l}\text { Enfrentam crises de valores com seus } \\
\text { pais e professores sobre o que é 're- } \\
\text { almente' importante no aqui e agora } \\
\text { virtual }\end{array}$ & $\begin{array}{l}\text { Não existe a fiscalização e muito me- } \\
\text { nos valores sobre o que é "virtualmente" } \\
\text { importante pois tudo é, quase sempre, } \\
\text { 'real'. }\end{array}$ \\
\hline $\begin{array}{l}\text { Procura de sua própria identidade e e } \\
\text { autonomia. O nome é importante }\end{array}$ & $\begin{array}{l}\text { Construção de uma lou várias) } \\
\text { versão(ões) virtual da identidade. } \\
\text { nome é substituído por senhas e logins }\end{array}$ \\
\hline Crescer demora muito tempo & Tudo é rápido e imediato \\
\hline
\end{tabular}

Fonte: Eisenstein e Estefenon (2011).

Observa-se, no quadro apresentado, como o universo digital responde diante das características dos adolescentes, atendendo aos anseios e necessidade e, ao mesmo tempo, às vulnerabilidades dessa faixa etária, que funde o real e o virtual, não os distinguindo nesse universo imediatista e ilimitado de relacionamentos, informações e realidades.

As referidas autoras destacam, a partir do quadro, o paradoxo existente na relação do adolescente penetrado nesse universo de informações, contatos e conexões e o isolamento que se mostra no meio da rede. Segundo as pesquisadoras, as crianças, adolescentes e jovens de hoje são curiosos, ágeis, têm acesso aos conhecimentos e sabem dos acontecimentos em tempo real por meio de seus celulares. Contudo, afirmam que existe a queda do rendimento escolar e a falta de diálogo, de comunicação e de afeto entre as 
famílias, ficando todos perdidos, e com dificuldade de conviver e lidar nas relações nesse mundo virtual, com seus códigos e regras próprias. Para essas pesquisadoras,

A linha limite que separa o uso produtivo e equilibrado da dependência da Internet do uso patológico, está cada vez mais tênue. Trata-se de uma questão de grau, não só do uso quantitativo das horas diante do computador, como também da qualidade dos conteúdos explorados na rede (EISENSTEIN; ESTEFENON, 2011 , p. 47).

Preocupações - como as apontadas pelas autoras acima - são citadas com frequência pela SaferNet Brasil (2017) - associação civil de direito privado, sem fins lucrativos e sem vinculação partidária ou religiosa, fundada em 2005, com atuação nacional, com foco na promoção e defesa dos Direitos Humanos na Internet no Brasil. Com o objetivo de transformar a Internet em um ambiente ético e responsável, essa instituição aponta para a preocupação do uso da Internet, pelos adolescentes, por tempo prolongado, sem análise do conteúdo acessado, aqui caracterizado quando há ausência de autocontrole ou ausência de controle por terceiros, mantendo atividade repetitiva e pouco criativa.

Tal preocupação justifica-se pelos dados estatísticos apontados pela Central Nacional de Denúncias de Crimes Cibernéticos, instituição criada e mantida pela organização acima apresentada, que já atendeu, entre 2007 e 2016, a mais de 13 mil pessoas, em 26 estados, que denunciaram quase 4 milhões de crimes como aliciamento sexual, conteúdos impróprios, violência, fraudes, entre outros relacionados às violações na Internet. Segundo a instituição citada, em 2016, a maioria absoluta dos atendimentos estava relacionada a conteúdo de ódio, violência, discriminação, intimidação e ofensa.

A inquietação por parte dos pais e dos profissionais da saúde e da educação quanto ao uso excessivo e aos conteúdos a que estão expostos as crianças e adolescentes também se justifica pela dificuldade nesse controle, uma vez que é crescente a mobilidade da tecnologia, e os dispositivos estão incorporados na vida de cada um, permitindo que fiquem sempre on-line.

Nesse sentido, Greensfield (2011) apresenta vários estudos que confirmaram a existência de um uso compulsivo ou dependente de Internet e mídias digitais (ABOUJAOUDE, KORAN, GAMEL, LARGE, SERPE, 2006; CHOU, 
Tecnologias móveis e relações interpessoais: reflexões sobre comportamento e aprendizagem

CONDRON, BELLAND, 2005; GREENFIELD, 2008; SHAW, BLACK, 2008; YOUNG, 20111.

De acordo com Greenfield (2011), esse uso excessivo está relacionado à adaptação e à atratividade das mídias digitais que, segundo o referido autor, conecta-se a cinco principais fatores, relacionados a seguir:

1. Fatores de conteúdo - estão associados à abundância de informações e ao prazer proporcionado por elas, como jogos, conteúdos sexuais, compras, entre outros.

2. Fatores de processo e acesso/disponibilidade - as facilidades de acesso e conveniência do anonimato, associadas ao fato de a Internet estar sempre aberta, com liberdade de uso 24 horas por dia, a custos acessíveis são, para o autor em questão, o que melhor caracteriza os fatores de processo e disponibilidade.

3. Fatores de reforço/recompensa - o desejo do conteúdo buscado, assim como o tempo e a frequência que esse produto poderá ser obtido afetam a experiência de atrelamento à Internet. Jogos, conteúdos sexuais, e-mail, compras ou navegação em busca de informações, sustentam, segundo o autor,

178 as estruturas de recompensa imprevisível e variável e garantem o princípio do reforço.

4. Fatores sociais - Greenfield (2011), fundamentado em várias pesquisas e estudos (GREENFIELD, 2008; KIMKIEWICZ, 2007; KRAUT, BRYNIN, KIESLER, 2006; EIJNDEN, MEERKERK, VERMULST, SPIJKERMAN, 2008; YOUNG, 20111, afirma que a Internet, ao mesmo tempo que conecta as pessoas, isola-as socialmente. Para o autor, existe uma conexão social calculada dentro de um ambiente de rede social circunscrito.

5. Fatores da Geração Digital (Generation Digital ou Gen-D) - Greenfield (2008) identifica como Gen-D as crianças e os adolescentes, nascidos a partir do início século XXI, que foram criados com a Internet e a tecnologia digital. A característica marcante dessa geração é a natural familiarização com o computador, a Internet, tablets, celulares e demais aparelhos digitais, sentindo-se confiantes no manejo dessa tecnologia.

Com base nas considerações do autor, sem desmerecimento de todas as conquistas da revolução tecnológica e os benefícios e avanços por ela trazidos, torna-se necessário reconhecer, trazer à consciência e desenvolver o 
uso das mídias digitais a favor e a serviço das relações interpessoais, entendendo como estas influenciam e determinam realidades e comportamentos, caminhando para o equilíbrio consciente, saudável e integrado do desenvolvimento da pessoa.

\section{Percurso metodológico}

O estudo ora descrito possui natureza exploratória na medida em que busca se aproximar do objeto e compreender seus limites, principais características e componentes. Embora os estudos sobre as relações emocionais e aprendizagens venham sendo analisados e discutidos há tempos por especialistas em educação e em psicologia, a influência das tecnologias digitais móveis, nos contextos pessoais, familiares e, especialmente, escolares representa nova problemática, para cujo entendimento se demanda novas análises e estudos.

Esta pesquisa de campo foi realizada junto aos alunos matriculados no nono ano de duas Escolas Municipais de São Caetano do Sul, localizadas em bairros distintos objetivando uma amostragem diversificada. Os alunos foram convidados a participar da pesquisa, voluntariamente, tendo a opção de declinar. $\bigcirc$ universo previsto contemplou cerca de 150 estudantes, estimando-se que sua totalidade possui dispositivo móvel digital. Os alunos do último ano do ensino fundamental (nono ano), na faixa etária entre 14 a 17 anos de idade, têm aula com o pesquisador e, portanto, constituem uma amostragem não- probabilística e de conveniência. Dessa forma, conclui-se que a amostragem por acessibilidade atendeu às necessidades desta pesquisa, uma vez que a análise acerca dos resultados deu-se de forma qualitativa (GIL, 2008).

Ainda, para melhor compreensão das respostas oferecidas, realizou-se entrevista on-line, no modelo de grupo focal, com dez alunos selecionados, respondentes e convidados a participar. A participação significativa desses estudantes permitiu aferir os fatores que tiveram maior influência entre aqueles apontados pela análise quantitativa. Essas entrevistas permitiram aprofundar os dados quantitativos obtidos.

questionário empregado nesse estudo foi o desenvolvido pelo Instituto Ayrton Senna, organização não governamental, criada em 1994, com foco de atuação na melhoria de qualidade da educação de crianças e jovens. 
Segundo o relatório de 2016, apresentado no site da organização, em 22 anos de trabalho e pesquisa, o Instituto Ayrton Senna mantém atuação em mais de 60 municípios, de 18 estados brasileiros, formando cerca de 50 mil educadores.

Entre as iniciativas de ação desenvolvidas pelo referido instituto, está a denominada Educação para o século XXI, a qual prevê o desenvolvimento de competências que vão além das já reconhecidas e avaliadas pelos sistemas educativos, como letramento e conceitos matemáticos. São as competências socioemocionais necessárias para aprender, viver, conviver e trabalhar em um mundo cada vez mais interativo, dinâmico e complexo.

Com base nessa frente de ação, o Instituto Ayrton Senna, em 2016, desenvolveu, em parceria com a Organização para a Cooperação e Desenvolvimento Econômico (OCDE), o primeiro instrumento escolar de mensuração de competências socioemocionais em larga escala no Brasil. Esse instrumento pertence a um sistema que integra a avaliação dessas competências às avaliações cognitivas existentes, permitindo o cruzamento dos resultados com informações de contexto socioeconômico e ambiente de aprendizagem. O sistema, batizado de SENNA (Social and Emotional Non-cognitive Nationwide Assessment), originado em Valdívia (2016), visa apoiar gestores e educadores na tarefa de formular, executar e reorientar políticas públicas e práticas pedagógicas destinadas a melhorar a qualidade da educação no Brasil.

$\bigcirc$ referido questionário, adaptado pelos pesquisadores responsáveis para atender aos propósitos e objetivos desta pesquisa, atua como proposta possível de avaliação dos fatores socioemocionais associados aos estudantes, permitindo indicar práticas que possam ser desenvolvidas e aprimoradas em escolas. Entende-se que a mensuração dos dados referentes às competências socioemocionais pode apresentar informações relevantes para promover a melhoria dos contextos de aprendizagem.

\section{Resultado da pesquisa}

Entendendo que o investimento nos aspectos socioemocionais é necessário para atender às necessidades dos alunos e melhorar a aprendizagem, uma vez que o desempenho cognitivo dos alunos é beneficiado quando esse grupo decisivo de competências é acionado e desenvolvido de forma 
intencional, este estudo pretende contribuir com a educação, em particular do município de São Caetano do Sul, que oportunizou a pesquisa. Mediante a apresentação da influência das emoções e das relações interpessoais na aprendizagem dos educandos, pretende-se nortear as ações dos docentes e equipe pedagógica no processo de formação dos estudantes, identificando dificuldades e desafios, na busca da qualidade do processo educativo escolar.

Os gráficos seguintes apresentam os resultados obtidos após a tabulação das respostas oferecidas pelos estudantes público-alvo desta pesquisa. Com base no referencial teórico apresentado anteriormente, as respostas oferecidas foram analisadas através da estatística descritiva, considerando os perfis socioemocionais apresentados pelos alunos e a utilização da tecnologia móvel digital para acesso às redes sociais por eles. A ênfase dada está, em especial, na percepção dos entrevistados em relação à influência e interferência das mídias digitais e redes sociais no contexto escolar de ensino e aprendizagem e em seus relacionamentos pertinentes ao núcleo familiar, parentes, amigos e colegas.

A análise das respostas ocorreu de forma integrada, buscando complementar informações para que houvesse uma coerente leitura interpretativa, com base nas evidências apresentadas nas respostas e na fundamentação exposta neste estudo.

\section{Gráfico 1}

\section{Tempo diário gasto para interagir nas redes sociais virtuais}

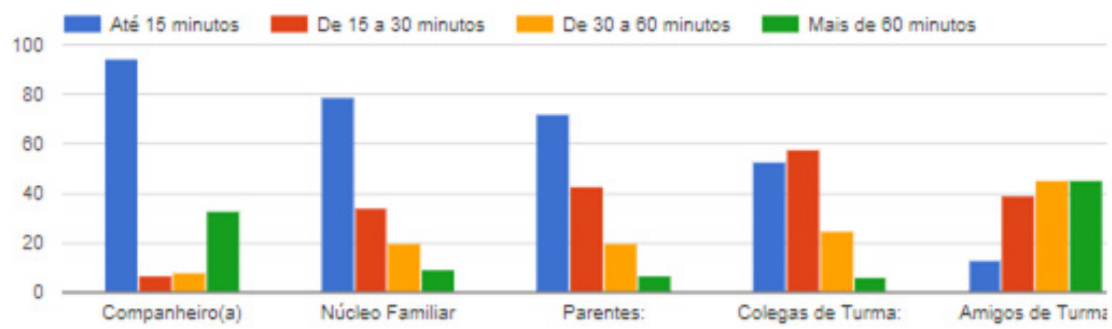

Fonte: os autores.

Neste gráfico, verificou-se que o tempo gasto com colegas e amigos é maior do que o tempo utilizado com familiares. 
As informações obtidas nos gráficos relacionados ao tempo de permanência nas redes sociais virtuais com cada núcleo de relacionamento revelam que as relações interpessoais entre os estudantes transcendem os muros da escola em tempo significativo.

Pode-se observar, com base na análise do gráfico 2, que mais de $50 \%$ dos jovens participantes permanecem conectados ativamente na Internet por tempo superior a 8 horas diárias. Esse dado nos remete aos estudos de Greenfield (201 1), apresentados ao longo desta pesquisa, os quais apontam os fatores que conduzem ao uso da Internet por período extenso.

\section{Gráfico 2}

\section{Tempo diário de utilização da Internet (em horas)}

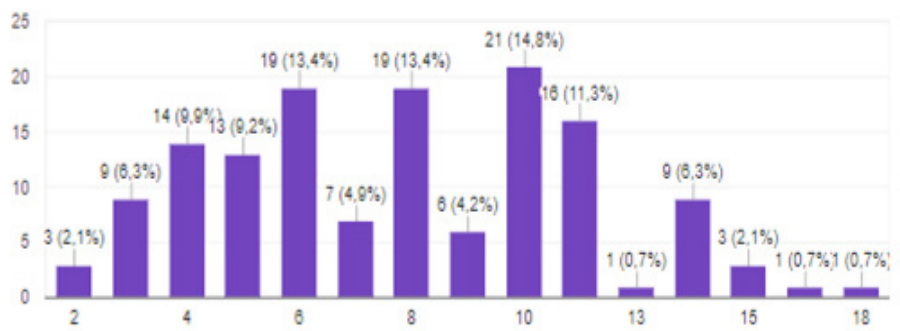

Fonte: os autores.

A facilidade de acesso, associada à atratividade dos conteúdos e à sensação de satisfação pela rapidez de se atingir o propósito esperado fazem com que essa ferramenta seja cada vez mais utilizada. Contudo, os estudos do referido autor também apresentam a paradoxal relação de aproximação e afastamento das relações interpessoais. Segundo Greenfield (2011), esse meio de comunicação permite que as relações sociais ocorram em um ambiente seguro e previsível, minimizando os níveis de atenção, risco emocional e conexão íntima, necessários no relacionamento social. Assim, o autor conclui, dizendo que a Internet, ao mesmo tempo que aproxima as pessoas, promovendo relações que independem da distância ou do espaço onde se encontram, as afasta do contato físico, inibindo habilidades necessárias para as relações proximais e presenciais.

Porém, conforme apresentado no decorrer deste estudo, não basta promover a análise isolada do tempo de uso da Internet pelas crianças e jovens. 
Não se pode julgar o uso da Internet como excessivo e prejudicial sem promover a análise ampla e complexa da totalidade que circunda o sujeito. Há de se considerar, sobretudo, a individualidade em cada caso, considerando contexto de vida, qualidade do conteúdo acessado, personalidade, ambiente social e cultural onde a pessoa está inserida. Desta forma, esta pesquisa possibilita a continuidade dos estudos, com aprofundamento em momento adequado, para análise junto aos jovens, pais e familiares de como se dá o aproveitamento do tempo destinado à Internet pelos estudantes participantes deste estudo.

\section{Gráfico 3}

Redes sociais virtuais utilizadas pelos participantes da pesquisa

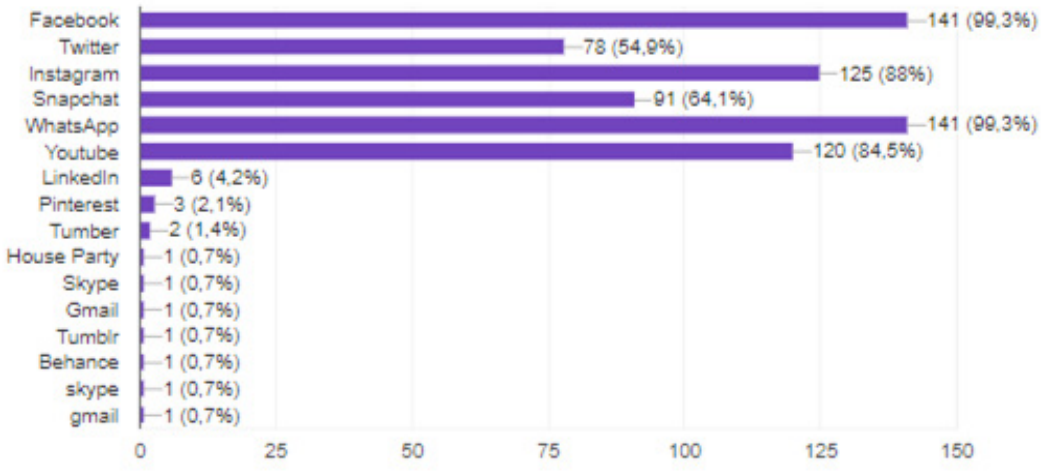

Fonte: os autores.

$\bigcirc$ gráfico 3, acima, mostra que todos os alunos participantes desta pesquisa estão conectados a, no mínimo 4 redes sociais, sendo o Facebook a rede social virtual que mais aparece, com 99,3\%.

Esta última informação merece destaque, uma vez que contraria o estudo da empresa de pesquisa norte-americana Forrester Research, o qual revelou, em 2015, que os jovens americanos estavam preferindo outras redes sociais. A pesquisa norte-americana foi realizada com 4.484 jovens americanos, com idade entre 12 a 17 anos, entre os quais, $78 \%$ ainda utilizam o Facebook, porém, 65\% desses adolescentes consideram essa rede social menos atrativa do que YouTube, Instagran e Snapchat, que receberam melhor avaliação, com cerca de 80\% de aprovação. Outras pesquisas, como a realizada pela ComScore, no mesmo ano, revela que o Facebook se mantém 
como a rede mais utilizada por atingir o público acima dos 35 anos. Contudo, apesar da tendência migratória dos jovens para outras redes sociais virtuais e, ainda, a utilização destas concomitantemente, o uso do Facebook aparece na quase totalidade dos entrevistados de São Caetano do Sul.

\section{Gráfico 4}

\section{Colegas e amigos presenciais que são também virtuais}

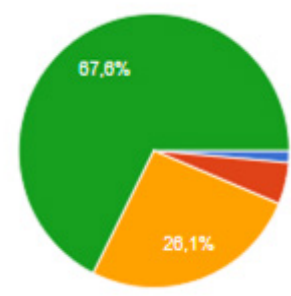

- Nenhum (0\%)

Poucos (até $20 \%$ )

Bastante (de $20 \%$ até $70 \%$ )

- Muitos (mais de $70 \%$ )

Fonte: os autores.

gráfico 4 sinaliza que 93,7\% dos entrevistados mantêm a relação

184 com os colegas e amigos presenciais também no âmbito virtual. Curioso apontar que a pesquisa revela, no gráfico 4 , aumento da quantidade de amizades através das redes sociais para 46,5\% dos jovens. Contudo, 39,4\% destes, sinalizam que as redes sociais pouco interferiram nessa quantidade, indicando que as amizades são construídas no espaço escolar, iniciando-se nas interações presenciais. Ressalta-se aqui a importância de trabalhar a qualidade dessas relações na escola, conforme apresentado nos estudos teóricos que fundamentam esta pesquisa, apontados por Goleman (2005), Chabot (2005), Gardner (1998) entre outros, entendendo que a busca por essa qualidade deve ser considerada também como propósito da educação.

A preocupação com o desenvolvimento das competências com Score necessárias para a qualidade das relações interpessoais e o impacto destas no aproveitamento dos conteúdos escolares também foi apontada no relatório do Instituto Ayrton Senna 'Educação para o século XXI', estudo que originou o formato do questionário utilizado nesta pesquisa. Segundo o documento citado, não há como desconsiderar as competências socioemocionais e as relações interpessoais no contexto escolar e o impacto destas no desempenho acadêmico dos estudantes, necessitando, portanto, que professores e demais 
membros da equipe pedagógica sejam habilitados para desempenhar um trabalho competente, que assegure o desenvolvimento de tais competências.

\section{Gráfico 5}

\section{Influência nos relacionamentos com amigos presenciais}

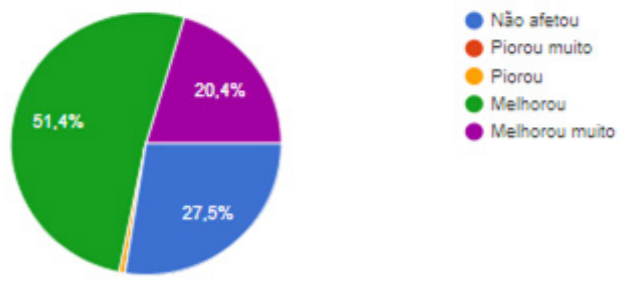

Fonte: os autores.

gráfico 5 mostra que 51,4\% dos entrevistados acreditam que, com a influência das redes sociais, houve avanço no relacionamento com os amigos, somados aos que acreditam que melhorou, substancialmente, o percentual, totalizando $71,8 \%$.

Após a breve apresentação dos dados, conclui-se, quanto à influência das redes sociais nos relacionamentos presenciais, que as respostas dos alunos que participaram dessa pesquisa levaram a algumas inquietações e questionamentos, expostos a seguir:

- Qual parâmetro foi utilizado pelos entrevistados para justificar que as redes sociais melhoraram ou pioraram a qualidade das relações presenciais se eles são nativos digitais, ou seja, as relações já nasceram constituídas e inseridas no contexto digital?

- $\bigcirc$ que se entende por piorar ou melhorar a relação?

Em face da necessidade da busca por entender melhor as respostas dadas para manter a coerência na análise das mesmas, evitando equívocos interpretativos que desviassem o resultado da pesquisa, optou-se por convidar um grupo de 10 participantes que responderam às perguntas acusando influência positiva das redes sociais sobre os relacionamentos presenciais.

Dessa forma, foi organizada uma videoconferência, no modelo de grupo focal, com o propósito de coletar informações através das interações 
Tecnologias móveis e relações interpessoais: reflexões sobre comportamento e aprendizagem

entre os participantes, a fim de esclarecer as dúvidas apontadas, optando pela análise qualitativa das respostas.

A conferência durou cerca de 90 minutos, mediados pelo pesquisador, que conduziu o debate com base nas questões levantadas. Pode-se afirmar que a participação foi intensa, com discurso coerente, que sugere a conclusão de que a "melhora" sinalizada pelos alunos está relacionada à ideia da não existência das redes sociais. Segundo os comentários do grupo focal, pensar nas relações sem as redes sociais acarretaria dificuldades na socialização, rapidez e dinamismo, hoje, vividos. Exemplos como escrever uma carta, torcer pela pessoa estar em casa ao fazer a ligação telefônica, ir ao encontro do outro para discutir um trabalho de escola, por exemplo, foram relatados pelo grupo para justificar que as redes sociais melhoraram os relacionamentos com amigos, colegas e parentes. Ao serem questionados se já viveram situações como as relatadas, enfatizando a escrita de cartas para a comunicação com alguém distante, todos os participantes do grupo foram unânimes ao afirmar que essa prática diz respeito a um passado longínquo para eles, vivido, apenas, pelos seus pais ou avós.

Assim, a resposta obtida na pesquisa não se refere, efetivamente, a 186 um comparativo real quanto à influência das redes sociais nos relacionamentos, mas ao imaginário dos alunos quanto a não existência das mesmas. $O$ mesmo, conclui o grupo, se refere a uma possível piora de esses relacionamentos sinalizados serem atribuídos às redes sociais virtuais. A denominação "piorou", utilizada, principalmente, nas relações com o núcleo familiar, diz respeito a responsabilizar as redes sociais virtuais frente ao problema existente nesse núcleo, imaginando que a não existência delas garantiria maior qualidade nessas relações familiares presenciais.

A conferência permitiu o estreitamento de laços interpessoais, em que o aluno sentiu-se valorizado e ativo nesta pesquisa. Ouvir o que os alunos tinham a dizer foi uma importante ação que os manteve coparticipantes do processo, ou seja, a conferência mostrou que, em uma ação significativa, que dá voz ativa ao aluno e o envolve efetivamente no processo, este assume a corresponsabilidade pelos resultados. Assim, entendendo que esta pesquisa não deve se findar em si mesma, após a conclusão do estudo, os alunos receberão o feedback dessa participação, permitindo a compreensão de todo o processo do qual participaram. 
Para concluir esta primeira análise de dados, ressalta-se a familiaridade dos jovens com a tecnologia, conforme os estudos de Eisenstein e Estefenon (201 1). Observou-se que 100\% dos entrevistados utilizam o dispositivo móvel e as redes sociais para comunicação e interação com o outro e com as informações disponíveis, expressando e validando as facilidades desse dispositivo nos relacionamentos interpessoais. Considerando-os nativos digitais, por nascerem em um contexto permeado pelo fácil e natural acesso à Internet e às redes sociais virtuais, infere-se que a citada influência das mídias sobre esses jovens acontece como determinante de comportamento, ou seja, utilizam-se do dispositivo para acessar os conhecimentos que desejam, para a troca de informações e comunicação entre os pares. Dessa forma, acostumam-se com a rapidez e facilidade de acesso promovido pelas redes sociais e todo o conteúdo disponível na Internet, conforme sinalizado por Greenfield (201 1), nos estudos que fundamentam esta pesquisa. A informação imediata, que atende à necessidade pontual torna-se suficiente. A escola precisa considerar a realidade atual e as características de sua clientela para que seus objetivos possam ser alcançados.

Em relação à análise das respostas, a atenção já é direcionada à opção dada pelos alunos quanto a concluir o dever de casa (gráfico 6). Mais de $40 \%$ apontam que o faz parcialmente, enquanto $26,4 \%$, apesar de fazer a maior parte do dever, ainda não o concluem e apenas 25,6\% afirmam que o realiza na totalidade. Essas respostas estão coerentes a uma das queixas dos professores quanto à não entrega dos trabalhos, estudos e tarefas solicitadas. Contudo, 72,5\% desses jovens entrevistados utilizam a Internet mais de 6 horas diárias, chegando a 18 horas de acesso, (gráfico 2) o que permite inferir que a gestão de tempo entre participação em redes sociais e realização do dever de casa não ocorre de forma equilibrada, com responsabilidade no cumprimento das tarefas. 


\section{Gráfico 6}

Ser capaz de concluir o dever de casa
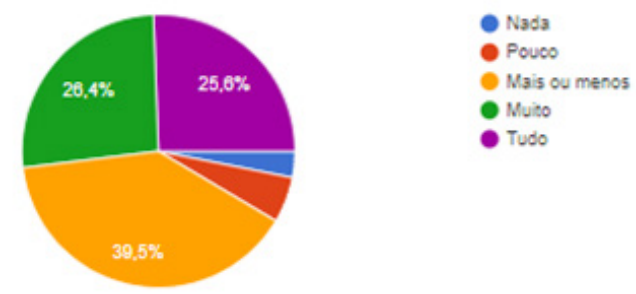

Fonte: os autores.

Conforme exposto e fundamentado por Greenfield (2011), a atratividade da Internet, disparada pelo dinamismo e rapidez de informações, além das novidades e facilidade de acesso tornam essa ferramenta mais atraente do que outros deveres, justificando o excesso de tempo destinado às mídias digitais. Corroborando o que diz o autor citado, os estudos de Einsestein e Estefenon (2011), expostos na fundamentação teórica que sustenta esta pesquisa, também esclarecem que a era digital está mudando comportamentos, moldados pelo imediatismo das informações proporcionado pela Internet, o qual atende às expectativas desses jovens, ao contrário do dever de casa costumeiramente encaminhado pelos professores, que demanda tempo, estudo e necessidade de construção e elaboração de respostas de forma mais estática.

\section{Gráfico 7}

Capacidade para se manter nos estudos mesmo tendo outras coisas interessantes para fazer

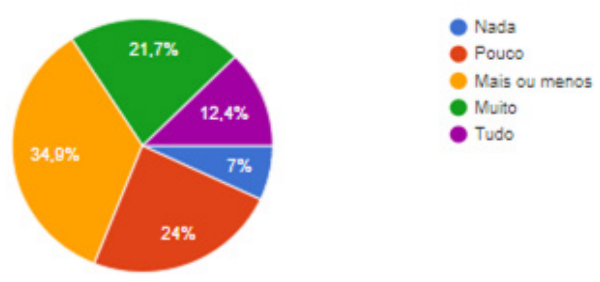

Fonte: os autores. 
Os dados do gráfico 7 podem ser interpretados quanto à capacidade de manter o foco nos estudos; isso não é tarefa simples para $65,9 \%$ dos alunos.

\section{Gráfico 8}

\section{Capacidade de prestar atenção nas aulas}

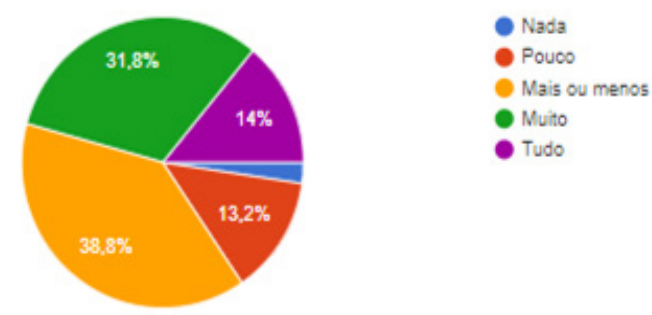

Fonte: os autores.

Coerente com a interpretação apresentada na análise do gráfico 6, outras questões, representadas nos gráficos 7 e 8 , sinalizam, respectivamente, que, para $65,9 \%$ dos alunos, não é fácil estudar diante de outras atividades interessantes a fazer e 54,2\% relatam a mesma dificuldade em prestar atenção às aulas.

Resgata-se aqui, conforme exposto anteriormente, a necessidade do envolvimento e interação entre o conteúdo a ser ensinado e as pessoas envolvidas, sendo papel do professor considerar necessidades e interesses dos alunos. Acreditando, portanto, que, para a aprendizagem acontecer precisa fazer sentido e ter significado para o aluno, a linguagem e os recursos utilizados podem ser considerados a ponte para essa significação, ou seja, a escola não pode desconsiderar o universo digital dessa geração.

Contudo, é importante ressaltar que a pesquisa foi feita com público, inserido em um contexto escolar com possibilidade de interação tecnológica, com acesso à Internet, computadores e lousa digital para fins acadêmicos em todas as salas de aula, ou seja, os recursos coerentes com a linguagem da Geração Digital, denominação apresentada por Greenfield (2011) para caracterizar os jovens nascidos a partir do século XXI, e que convivem com as redes sociais digitais naturalmente, estão acessíveis e disponíveis para a aprendizagem. Dessa forma, a dificuldade em prestar atenção às aulas e executar o dever de casa torna-se uma inquietação, merecedora de estudo mais 
aprofundado com esse foco. Infere-se, com base nos estudos apresentados, que a escola vem gastando grande energia na disputa com as mídias digitais para obter atenção do aluno. Não basta ter disponível a tecnologia se esta não estiver a serviço desta geração que domina o universo digital.

\section{Gráfico 9}

\section{Conseguir ter bom desempenho em uma prova}
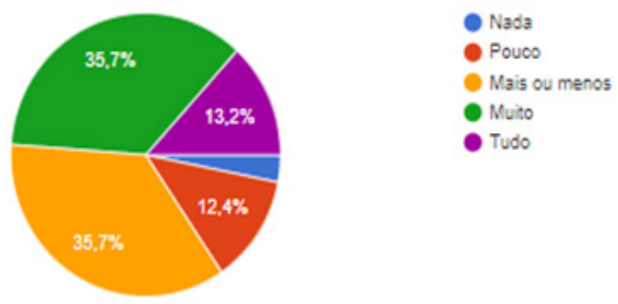

Fonte: os autores.

Completando os dados apontados anteriormente, verifica-se que, apenas, 48,9\% responderam que conseguem, efetivamente, ter um bom desempenho em uma prova (gráfico 9). Nesse sentido, pode-se inferir que a expectativa de ensino e aprendizagem dos conteúdos escolares proposta pela escola se afasta dos reais interesses do aluno, ou daquilo que chama sua atenção, o que corrobora a ideia de que o estudo, da forma como aplicado nas escolas, vem perdendo cada vez mais espaço para o universo digital, permeado pelas interações nas redes sociais e navegação na Internet.

\section{Considerações finais}

Retomar constantemente o papel da escola e sua função social na perspectiva do processo efetivo de ensino e aprendizagem e os elementos que perpassam e influenciam tal processo deve ser prática constante na ação do professor que se preocupa em garantir o direito do aluno às aprendizagens e ao conhecimento acadêmico. Nessa perspectiva, resgatam-se a aprendizagem significativa e o papel do docente na construção do conhecimento em um contexto permeado de relações inter e intrapessoais, no qual o profissional assume a importante função de mediar as relações para que estas estejam a favor das aprendizagens. 
Nesse processo, o professor necessita desenvolver o olhar sensível e atento às características dos alunos, atuando a partir da leitura do contexto e dos comportamentos e emoções que compõe a dinâmica da aula. Diversos autores, conforme apresentados neste estudo, apontam que não se pode mais considerar que as emoções e sentimentos não interferem na aprendizagem das crianças e jovens, seja qual for a cultura em que está inserido. As pesquisas, apontadas neste estudo por Chabot e Chabot (2005), Goleman (2005), Gardner (1998), entre outros, constituem base para tal afirmação, deixando evidente que competências técnicas e os conteúdos disciplinares não são suficientes para a formação integral do ser.

Por outro lado, os dados obtidos, no decorrer da pesquisa, informam que o formato atual, oferecido por nossas escolas, não é adequado à compleição dos nossos alunos, tendo em vista que, segundo os entrevistados, são bem-intencionados, gostam de aprender novidades, e se consideram interessados quanto a novos conteúdos. Contudo, afirmam que não conseguem prestar atenção às aulas, o que aponta para o sentido de que o elo faltante se dá na interação entre o aluno e o conteúdo proposto pela escola. Percebe-se, claramente, que existe a vontade do aluno e o propósito da escola. Pode-se inferir, entre outras variáveis, que faltam alternativas mais sedutoras aos educandos, no que se refere à informação transmitida para que ela se torne conhecimento; isso implica dizer que melhorias podem ser feitas, multimeios utilizados, para a condução dessa informação.

Nesse contexto de aprendizagem escolar, permeado por relações e interaç̃ẽes, as competências relacionadas à inteligência emocional, apontadas por Goleman (2005), voltadas para o autoconhecimento e controle emocional, automotivação, reconhecimento de emoções em outras pessoas e habilidade em relacionamentos pessoais devem ser considerados no contexto da sala de aula, por se tratar de espaço privilegiado de relações. Lidar com divergências e conflitos que surgem no decorrer dessas relações deve ser considerado potencial de desenvolvimento de habilidades, não limitando esse trabalho à contenção punitiva, desprovida de reflexão e aprendizagem do grupo. Desta forma, um olhar refinado, que perpassa as primeiras barreiras imposta pelo aluno, é indispensável ao professor que deseja êxito no processo aprendizagem.

Considerando o jovem estudante, nascido no século XXI, um nativo digital, ou seja, imerso na tecnologia móvel desde o nascimento, nas quais as 
mídias exercem influência no comportamento e hábito apresentado, há de se considerar que ele apresenta características próprias, entre elas, o pensamento em rede, através de diferentes linguagens e formatos. Nessa perspectiva, o sistema atual de ensino, que trabalha na linearidade dos conteúdos destacados em disciplinas independentes, não corresponde a esse novo formato. Eisenstein e Estefenon (2011), e Greenfield (2011) serviram de base para tal afirmação e revelam que a Internet exerce impacto visível no desenvolvimento, desempenho escolar e social dos jovens.

Infere-se, com base no exposto, que não há como desconsiderar a influência do mundo digital sobre o comportamento, forma de pensar e agir dos jovens; desconectar a sala de aula desse universo distancia o aluno dos propósitos da escola.

Coerente com os estudos teóricos levantados, a pesquisa de campo, realizada junto aos alunos das duas escolas de São Caetano do Sul, mostra que o estudante permanece considerável parte de sua rotina imerso a um dispositivo móvel, utilizando, no mínimo, quatro redes sociais para sua interação com outras pessoas, passando até 18 horas conectados aos dispositivos móveis digitais. Esse dado merece atenção pois, considerando Greenfild (201 1), ao mesmo tempo que a Internet aproxima as pessoas, potencializando as relações humanas, está também afastando das relações físicas entre as pessoas. Sendo a escola um espaço de interações presenciais, compete aos agentes que dela fazem parte investir em ações que desenvolvam a qualidade dessas relações

À escola compete assegurar seu objetivo central de desenvolver aprendizagens, transformando informações em conhecimentos reais, construindo competências nos aspectos cognitivos e sociais, ampliando o repertório acadêmico, científico, linguístico, artístico e cultural nas mais diversas áreas de conhecimento. Contudo, no mundo globalizado, com informações facilmente acessíveis, para o manejo de tal repertório é fundamental que as pessoas tenham competências relacionais e emocionais bem desenvolvidas, ou seja, considera-se essencial a integração indissociável entre o conhecimento técnico e acadêmico e as competências socioemocionais e relações interpessoais.

Dessa forma, considerando seu público, a educação atual precisa estar voltada à perspectiva da formação integral, a qual não prevê o distanciamento na relação professor-aluno e almeja a união dos aspectos cognitivo e emocional, entendendo que a aprendizagem efetiva ocorrerá através da 
consideração e exploração das emoções que perpassam o cotidiano escolar. Para atingir esse propósito, o presente estudo busca a transformação do cenário atual através da formação continuada do professor, para que ele perceba sua importância nesse processo, possibilitando ao docente compreender a influência do relacionamento interpessoal entre professor e aluno, e entre os pares, no desempenho acadêmico e desenvolvimento pessoal, possibilitando, ainda, a reflexão acerca da interferência da tecnologia nessa relação no espaço escolar.

estudo aqui apresentado tem o propósito de auxiliar o professor no processo de formação docente, visando à identificação de competências e comportamentos dos alunos para reflexão e levantamento de estratégias de ação para atingir os fins educacionais propostos pela escola, garantido a todos os educandos o direito à aprendizagem efetiva, considerando potenciais e comportamentos dos atuais jovens nativos digitais.

\section{Referências}

ABOUJAOUDE, Elias; KORAN, Lorrin; GAMEL, Nona; SERPE, Richard. Potential markers for problematic Internet use: a telephone survey of 2.513 adults. The International Journal of

Neuropsychiatric Medicine, New York, v. 1 1, p. 750-755, 2006.

ARISTOTLE. Aristotle Quotes. Disponível em: https://www. brainyquote.com/authors/aristoHe. Acesso: em 12 dez. 2017.

BOLSONI-SILVA, Alessandra Turini; MARTURANO, Edna Maria. Práticas educativas e problemas de comportamento: uma análise à luz das habilidades sociais. Estudos de Psicologia. Campinas, v. 7, n. 2, p. 227-235, jul./dez. 2002.

CHABOT, Daniel; CHABOT, Michel. Pedagogia emocional: sentir para aprender. São Paulo: Sá Editora, 2005.

CHOU, Chien; CONDRON, Linda; BELLAND, John C. A review of the research on Internet addiction. Educational Psychology Review, v. 17, n. 4, p. 363-388, dec. 2005.

EIJNDEN, Regina van den; MEERKERK, Gert-Jan.; VERMULST, Ad; SPIJKERMAN, Renske. Online communication, compulsive Internet usage, and psychosocial well-being among adolescents: a longitudinal study. Developmental Psychology, Washington, v. 44, n. 3, p. 655-665, mayo 2008. 
Tecnologias móveis e relações interpessoais: reflexões sobre comportamento e aprendizagem

EISENSTEIN, Evelyn; ESTEFENON, Susana. Geração Digital: riscos das novas tecnologias para crianças e adolescentes. Revista Hospital Universitário Pedro Ernesto, Rio de Janeiro, v. 10, n. 2, p. 42-52, 2011.

FERREIRA, Marlene Cassia Trivellato; MARTURANO, Edna Maria. Ambiente familiar e os problemas de comportamento apresentados por crianças com baixo desempenho escolar. Psicologia: Reflexão e Crítica, Porto Alegre, v. 15, n. 1, p. 35-44, 2002.

GARDNER, Howard. Inteligência: múltiplas perspectivas. Porto Alegre: Artmed, 1998.

GIL, Antônio Carlos. Métodos e técnicas em pesquisa social. 6. Ed. São Paulo: Atlas, 2008.

GREENFIELD, David. Virtual addiction: clinical implications of digital \& Internet- enabled behavior. Presentation at the International conference course about new technologies: Addiction to new technologies in adolescents and young people, Auditorium Clinic Hospital, Madrid, Spain, 2008.

As propriedades de dependência do uso de Internet. In: YOUNG, Kimberly; ABREU, Cristiano Nabuco de. Dependência de Internet: manual e guia de avaliação e tratamento. Porto Alegre: ARTMED, 2011.

GOLEMAN, Daniel. Inteligência emocional. Rio de Janeiro: Objetiva, 2005.

KLIMKIEWICZ, Joann. Internet junkies: hooked online. Hartford Courant. Disponível em: https://tinyurl.com/ycde2je9. Acesso em: 12 nov. 2007.

Kraut, Robert; BRYNIN, Malcolm; KIESLER, Sara. Computers, phones, and the Internet. Oxford University Press, 2006.

SAFERNET. SaferNet Brasil. Disponível em: www.safernet.org.br. Acesso em: 15 dez. 2017.

SHAW, M. \& BLACK, D. W. Internet addiction: definition, assessment, epidemiology and clinical management. CNS Drugs, n. 22, p. 353-365, 2008.

VALDIVIA, Gina Pamela Pancorbo. Propriedades psicométricas do inventário social and emotional (or noncognitive) nationwide assessment (SENNA). 2016. 88f. Dissertação (Mestrado em Psicologia) - Programa de Pós-Graduação em Psicologia, Universidade de Brasília, Brasília, 2016.

YOUNG Kimberly; ABREU, Cristiano Nabuco. Dependência de Internet. Porto Alegre: Artmed, 2011.

WALLON, Henry. As origens do caráter na criança. São Paulo: Difusão Europeia do Livro, 1971. 
WEISSBERG, Michael. Dangerous secrets: maladaptive responses to stress. New York: W. W. Norton, 1983.

Prof. Ms. Magnus Guerreiro Thomazini Universidade Municipal de São Caetano do Sul Programa de Mestrado Profissional em Educação

Pró-Reitoria de Pós-Graduação e Pesquisa Grupo de Pesquisa ETICO

E-mail: prof.magnusthomazini@gmail.com

Prof. Dr. Elias Estevão Goulart Universidade Municipal de São Caetano do Sul Pró-Reitoria de Pós-Graduação e Pesquisa Programa de Mestrado Profissional em Educação Líder do Grupo de Pesquisa ETICO E-mail: elias.goulart@uscs.edu.br Recebido 11 jun. 2018 Aceito 11 ago. 2018 